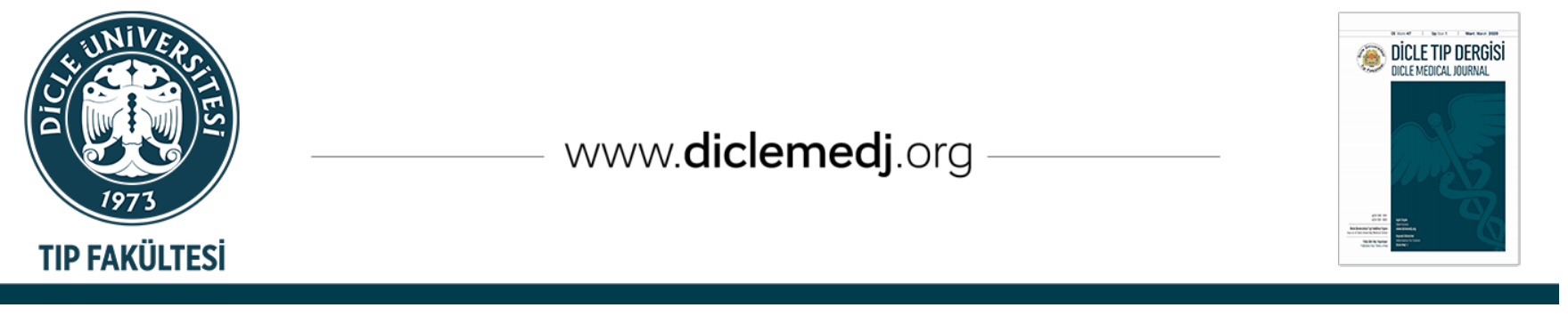

\title{
Bilgisayarlı Tomografi Eşliğinde PerkütanTranstorasik Akciğer Biopsilerinin Değerlendirilmesi: Tek Merkez Deneyimi
}

\author{
Muhammed Akif Deniz ${ }^{i}{ }_{1}$,Zelal Taş Deniz ${ }^{i{ }_{2}}$, Salih Hattapoğlu ${ }^{i}{ }_{1}$, Mehmet GuliÇetinçakmak ${ }^{\text {iD }}$, \\ Osman Kurt $\mathrm{DD}_{4}$
}

1 Dicle üniversitesi Tıp Fakültesi, Radyoloji Anabilim Dalı, Diyarbakır,Türkiye

2 Sağlık Bilimleri Üniversitesi Gazi Yaşargil Eğitim Araştırma Hastanesi Radyoloji Kliniği, Diyarbakır,Türkiye

3 Özel Memorial Hastanesi Radyoloji Kliniği, Diyarbakır, Türkiye

4 Fırat Üniversitesi Tıp Fakültesi, Halk Sağlığı Anabilim Dalı Elazı̆̆,Türkiye

Geliş: 09.04.2020; Revizyon: 01.07.2020; Kabul Tarihi: 06.07.2020

$\ddot{0} \mathbf{z}$

Giriș: Akciğer yerleșimli kitlelerde bronkoskopi, perkutan biyopsi, torakoskopik cerrahi ile biyopsi ve açık cerrahi biyopsiler bașlıca biyopsi alma teknikleridir. BT kitlenin sınırlarını, komşuluklarını, yayılımını,natürünü, akciğer parankiminde eşlik eden patolojiyi görüntülemede son derece duyarlı olduğundan hem tanı hem de toraks biyopsilerinde önemli bir yer tutmaktadırlar. Amacımız kliniğimizde BT eșliğinde trucutbiopsi yapılmıș akciğer parankim kitlelerinin radyolojik özelliklerini, tanısal biopsi oranını, komplikasyon oranlarını çeşitli parametreler eşliğinde değerlendirmeyi ve biopsi etkinliğini değerlendirmektir.

Yöntemler: Çalışmamız retrospektif arşiv çalışması olup Mart 2013-Aralık 2019 tarihleri arasında BT eşliğinde akciğer parankim kitlesine trucutbiopsi yapılmış hastalar çalışmaya dahil edilmiştir.

Hastalar yaș, cinsiyet, lezyon çapı, lezyonun akciğer ve segmenter lokalizasyonu, lezyonun radyolojik özelliği, biopsi sırasında hasta pozisyonu, biopsi sırasında iğnenin akciğer parankimindeki uzunluğu ve komplikasyon (pnömotoraks ve hemoraji) açısından değerlendirilmiștir.

Bulgular: Çalışmaya alınan 336 hastanın yaş ortalaması 62,12 $\pm 12,48$ (min=15-maks=90) idi. Biopsi yapılan lezyonlar en sık \%62,5 sağ akciğer ve \%53 üst lobda yerleşimliydi. Lezyonların yapısı $\% 46,4$ konsolidasyon, $\% 41,4$ nodüler, $\% 8$ kaviter ve $\% 4,2$ infiltrasyon şeklindeydi. Lezyon çapı ortancası $35,5(49,0-23,50) \mathrm{mm}$ olarak, iğne giriş uzunluğu ortancası ise $14,5(26,0-9,0) \mathrm{mm}$ olarak bulundu. Hastalar en fazla prone pozisyonunda (\%41,4) işleme alındı. Hastaların 115 'inde (\%34,2) komplikasyon geliști. Bu komplikasyonların \%52,2' si pnömotoraks ve \%47,8' i hemorajiydi. Komplikasyon olarak pnömotoraks gelișen 60 hastanın 7'sine $(\% 11,7)$ toraks tüpü takıldı. İğne giriş uzunluğunun çeşitli değişkenlere göre incelemesi yapıldığında komplikasyon gelişen hastalardaki iğne giriş uzunluğu ortancası komplikasyon gelişmeyen hastaların ortancasından anlamlı şekilde yüksek bulunmuştur $(\mathrm{p}=0,005)$

Tartışma-sonuç: Sonuç olarak akciğer kitlelerinde Trucut biopsi yapılmış hastalarımızda tanı oranı yüksek, komplikasyon oranı düşük olarak izlendi. BT akciğer kitle biopsilerinde kolay uygulanabilen, komplikasyonu erken dönemde gösterebilen oldukça etkin bir yöntemdir.

Anahtar kelimeler: Toraks, Kitle, Transtorasik Biopsi, Bilgisayarlı Tomografi.

DOI: 10.5798/dicletip.800255

Correspondence / Yazışma Adresi: Muhammed Akif Deniz, Dicle Üniversitesi Tıp Fakültesi Radyoloji Anabilim Dall, 21280Diyarbakır,Türkiye e-mail: makifdeniz@yahoo.com 


\title{
Evaluation of Computed tomography-guided percutaneous lung biopsies: Single Center Experience
}

\begin{abstract}
Objective: Bronchoscopy, percutaneous biopsy, thoracoscopic surgery biopsy and open surgical biopsies are the main biopsy techniques in lung masses.Computed Tomography has an important place in both diagnosis and thorax biopsies, as it is extremely sensitive in imaging the borders, neighborhood, spread, nature, and accompanying pathology of the lung parenchyma.

Our aim is to evaluate the radiological features, diagnostic biopsy rate, complication rates, and biopsy efficacy of the lung parenchymal masses that have undergone trucut biopsy in our clinic

Methods: Our study was a retrospective archive study, and patients who underwent CT-treated lung parenchymal mass between March 2013 and December 2019 were included in the study. Patients were evaluated in terms of age, gender, lesion diameter, lung and segmental localization of the lesion, radiological feature of the lesion, patient position during biopsy, length of the needle in the lung parenchyma during biopsy, and complications (pneumothorax and hemorrhage)

Results: The average age of 336 patients included in the study was $62.12 \pm 12.48$ ( $\min =15-\max =90)$. Biopsied lesions were most frequently located in the right lung and $62.5 \%$ in the upper lobe. $46.4 \%$ of the lesions were consolidation, $41.4 \%$ were nodular, $8 \%$ were cavitary and $4.2 \%$ were infiltrated. The median diameter of the lesion was $35.5(49.0-23.50) \mathrm{mm}$, and the median of needle entry length was $14.5(26.0-9.0)$ $\mathrm{mm}$. The patients were processed in the most prone position (41.4\%). Complications developed in $115(34.2 \%)$ of the patients. $52.2 \%$ of these complications were pneumothorax and $47.8 \%$ were hemorrhage. As a complication, 7 of the 60 patients who developed pneumothorax / $11.7 \%$ ) received a thorax tube. When the needle entry length was examined according to various variables, the median of needle entry length in patients who developed complications was significantly higher than the median of patients who did not develop complications ( $\mathrm{p}=0.005$ ).

Conclusion: As a result, in our patients who underwent trucut biopsy in their lung masses, the rate of diagnosis was high and the complication rate was low. BT is a very effective method that can be applied easily in lung mass biopsies and can show complications in the early period.
\end{abstract}

Keywords: Thorax, Mass, Transthoracic Biopsy, Computed Tomography.

\section{GíRiş}

Akciğer yerleşimli kitlelerde bronkoskopi, perkutan biyopsi, torakoskopik cerrahi ile biyopsi ve açık cerrahi biyopsiler başlıca biyopsi alma teknikleridir. Bronkoskopik biopsi endobronşial veya peribronşial lezyonlar için uygun bir yöntemdir. Açık cerrahi biyopsiler büyük örnekler elde edilmesini sağlamakla birlikte mortalite ve morbiditesi yüksek işlemlerdir ${ }^{1}$. Radyolojik yöntemler eşliğinde perkütan toraks biyopsileri ultrason, bilgisayarlı tomografi (BT) ve daha nadiren floroskopi eşliğinde yapılabilmektedir. Ultrason eşliğinde yapılan biopsiler daha çok gögüs duvarına yakın lezyonlarda uygun bir tekniktir. Ancak akciğer kitlelerinin önemli bir kısmı parankimal yerleşimli olduğundan ultrason ile görüntülenememektedirler. BT kitlenin sınırlarını, komşuluklarını, yayılımını, natürünü, akciğer parankiminde eşlik eden patolojiyi görüntülemede son derece duyarlı olduğundan hem tanı hem de toraks biyopsilerinde önemli bir yer tutmaktadırlar.
Aynı zamanda BT eşliğinde yaplan biopsilerde komplikasyonu değerlendirmek için işlemden hemen sonra erken evrede görüntüleme yapılabilmesi önemli bir avantajdır. Tüm bu avantajları sayesinde BT akciğer kitle biopsilerinde oldukça sık kullanılan bir yöntemdir ${ }^{1-3}$.

Bu çalışmada, kliniğimizde BT eşliğinde trucut biopsi yapılmış akciğer parankim kitlelerinin radyolojik özelliklerini, tanısal biopsi oranını, komplikasyon oranlarını çeşitli parametreler eşliğinde değerlendirmeyi ve biopsi etkinliğini değerlendirmeyi amaçladık.

\section{YÖNTEMLER}

Çalışmamız retrospektif arşiv çalışması olup Mart 2013-Aralık 2019 tarihleri arasında girişimsel radyoloji ünitemizde BT eşliğinde akciğer parankim kitlesine trucut biopsi yapılmış hastalar çalışmaya dahil edilmiştir. Çalışmamız Dicle üniversitesi Tıp Fakültesi Girişimsel olmayan Klinik Araştırmalar Etik 
Kurulundan 09.01.2020 tarih ve 88 sayı numarası ile onay alınmıștır.

Hastalar yaş, cinsiyet, lezyon çapı, lezyonun akciğer ve segmenter lokalizasyonu, lezyonun radyolojik özelliği, biopsi sırasında hasta pozisyonu, biopsi sırasında iğnenin akciğer parankimindeki uzunluğu açısından değerlendirilmiştir. İşlem sonrası alınan görüntülerde komplikasyon olarak pnömotoraks ve parankimal hemoraji açısından değerlendirilme yapılmıştır. Pnömotoraks gelişen hastalarda drenaj amaçlı göğüs tüpü gereksinimi bulunan hastalar da ayrica belirtilmiştir.

Akciğerde kitle tanısı olan ancak bilgisayarlı tomografi dışında bir görüntüleme yöntemiyle (floroskopi, ultrasonografi) yapılan biopsiler, işleme başlanmış olmakla birlikte (hasta isteği, aşırı ağrı, hasta uyumsuzluğu gibi nedenlerle) işlemin sonlandırılmadığı hastalar, BT eşliğinde biopsi yapılmış olmasına rağmen görüntüleri sistemimizde olmayan hastalar çalışma dışı bırakılmıştır. Ayrıca BT eşliğinde biopsi yapılmış olmasına rağmen akciğer parankimi ile ilgisi olmayan toraks duvar ve kosta biopsileri de çalışma dışı bırakılmıștır.

\section{Biopsi Tekniği}

İşlem öncesi hastalarda kanama parametrelerine bakıld. Antiagregan ve antikoagulan kullanan hastalarda ilaçlar 4-7 gün önceden kesildi. Hastalara intravenöz damar yolu açıldı ve hastalar tercihen 8-10 saatlik açlığı takiben işleme alındı. Hastaların vital fonksiyonları monitörize edilip ve oksijen saturasyonu yakın takip edildi. İşlem öncesi kitlenin mevcut durumunu görebilmek amacıyla BT görüntüsü alındı. Hastalar, kitlenin görülebildiği, fissürlerin geçilmeyeceği ve parankimal alandan en az geçilecek şekilde güvenli bir giriş açısının bulunduğu şekilde supin, prone veya lateral pozisyonda yatırıldı. Cilt işaretleyici ile kitleye ulaşım açısından en uygun açı belirlendi. Steril şartlarda giriş yerine ortalama 8-10 cc \%2'lik lidokain ile plevraya ulaşmayacak şekilde (pnömotoraks riski nedeniyle) lokal anestezi yapıldı. Ardından fissür geçilmeyecek bir açı ile hastaya nefes tuturularak yarı otomatik koaksiyel iğne, kitle düzeyine kadar gönderildi. Seri görüntülerle iğne ucu kontrol edildi. Pnömotoraksı engellemek için plevral yapraklar birden fazla geçilmedi. Ardından madren çıkarılıp koaksiyel iğne içerisinden $18 \mathrm{G}$ kesici iğne gönderildi ve en az iki adet materyal alındı. İşlem sonrası erken dönem komplikasyonlar açısından kontrol BT görüntüleme yapıldı Tüm hastalara komplikasyon açısından 2-4-6. ve 24. saatlerde kontrol akciğer grafisi yapıldı.

\section{Verilerin Analizi}

Çalışmada elde edilen bulgular değerlendirilirken, istatistiksel analizler için SPSS 22.0 programı kullanılmıştır. Kategorik veriler sayı ve yüzde şeklinde, ölçümsel verilerde yaş ortalama ve standart sapma şeklinde, lezyon çapı ve iğne giriş uzunluğu verileri medyan interquartilerange (25-75 persantil değerleri) şeklinde gösterilmiştir. Kategorik verilerin karşılaştırılmasında Kikare analizi kullandı. Çalışma verileri değerlendirilirken parametrelerin normal dağılıma uygunluğu Kolmogorov-Smirnov testi ile değerlendirilmiştir. Niceliksel verilerde normal dağılım göstermeyen parametrelerin karşıllaştırmalarında bağımsız gruplarda t testi, Mann-Whitney U testi ve KruskalWallis testi kullanılmıştır. Anlamlılı̆̆ın nereden kaynaklandığını bulabilmek için Post Hoc testi kullanıldı. İki ölçümsel verinin karşılaştırılması için Spearman korelasyon analizi kullanıldı. Anlamlılık p $<0.05$ düzeyinde değerlendirilmiştir.

\section{BULGULAR}

Çalışmaya alınan 336 hastanın yaş ortalaması $62,12 \pm 12,48$ ( $\mathrm{min}=15-$ maks=90) idi. Çalışmaya 255 $(\% 75,9)$ erkek ve $81(\% 24,1)$ kadın dahil edilmiştir. Erkeklerin yaş ortalaması $62,47 \pm 12,57$ olarak, kadınların yaş ortalaması ise $61,01 \pm 12,19$ idi.

Çalışmaya alınan hastaların lezyon yerleşimi incelendiğinde en sık 210 'u $(\% 62,5)$ sağ akciğer ve 178 'i $(\% 53,0)$ üst lobda yerleşimliydi. Lezyonların 156'sı (\%46,4) konsolidasyon, 139'u (\%41,4) 
nodüler, 27'si $(\% 8,0)$ kaviter ve 14'ü $(\% 4,2)$ ise infiltrasyon yapısındaydı. Eşlik eden lezyonlar değerlendirildiğinde 32 'sinde $\quad(\% 9,5)$ amfizem mevcuttu. Hastalar sirasiyla en sik prone pozisyonunda $(\% 41,4)(O l g u 1)$ ve supin pozisyonda $(\% 32,1)$ (Olgu 2) işleme alındı. Altmış hastada $(\% 52,2)$ pnömotoraks ve 55 hastada $(\% 47,8)$ ise hemoraji olmak üzere toplam115 hastada $(\% 34,2)$ komplikasyon gelişti(Olgu 3). Komplikasyon olarak pnömotoraks gelișen 60 hastanın 7'sine (\%11,7) toraks tüpü takıldı. Hastaların 316'sına tanı konulmuş olup 20 hastada (\%6) tanı konulamadı. Tanısı konulan hastaların 77'si $(\% 24,4)$ benign (en sık antrakozis) iken, 239'u (\%71,1) malign (en sık adenokanser) idi (Tablo 1).

Tablo I: Lezyonun Özellikleri, Hasta Pozisyonu ve Komplikasyon Durumu

\begin{tabular}{|c|c|c|c|}
\hline & & Sayı & $\%$ \\
\hline \multirow{2}{*}{ Lokalizasyon } & Sağ & 210 & 62,5 \\
\hline & Sol & 126 & 37,5 \\
\hline \multirow{3}{*}{ Segment } & Üst lob & 178 & 53,0 \\
\hline & Orta lob & 47 & 14,0 \\
\hline & Alt lob & 111 & 33,0 \\
\hline \multirow{4}{*}{ Lezyon yapısı } & Nodüler & 139 & 41,4 \\
\hline & Kaviter & 27 & 8,0 \\
\hline & İnfiltrasyon & 14 & 4,2 \\
\hline & Konsolidasyon & 156 & 46,4 \\
\hline \multirow{2}{*}{ Eşlik eden lezyon } & Amfizem yok & 304 & 90,5 \\
\hline & Amfizem var & 32 & 9,5 \\
\hline \multirow{3}{*}{ Pozisyon } & Supin & 108 & 32,1 \\
\hline & Lateral & 89 & 26,5 \\
\hline & Prone & 139 & 41,4 \\
\hline \multirow{2}{*}{ Komplikasyon } & Var & 115 & 34,2 \\
\hline & Yok & 221 & 65,8 \\
\hline \multirow{2}{*}{ Komplikasyon Çeşidi } & Pnömotoraks & 60 & 52,2 \\
\hline & Hemoraji & 55 & 47,8 \\
\hline \multirow{2}{*}{$\begin{array}{l}\text { PnömotorakstaToraks Tüpü } \\
\text { Gereksinimi }\end{array}$} & Var & 7 & 11,7 \\
\hline & Yok & 53 & 88,3 \\
\hline \multirow{2}{*}{ Tanı } & Benign & 77 & 24,4 \\
\hline & Malign & 239 & 75,6 \\
\hline
\end{tabular}

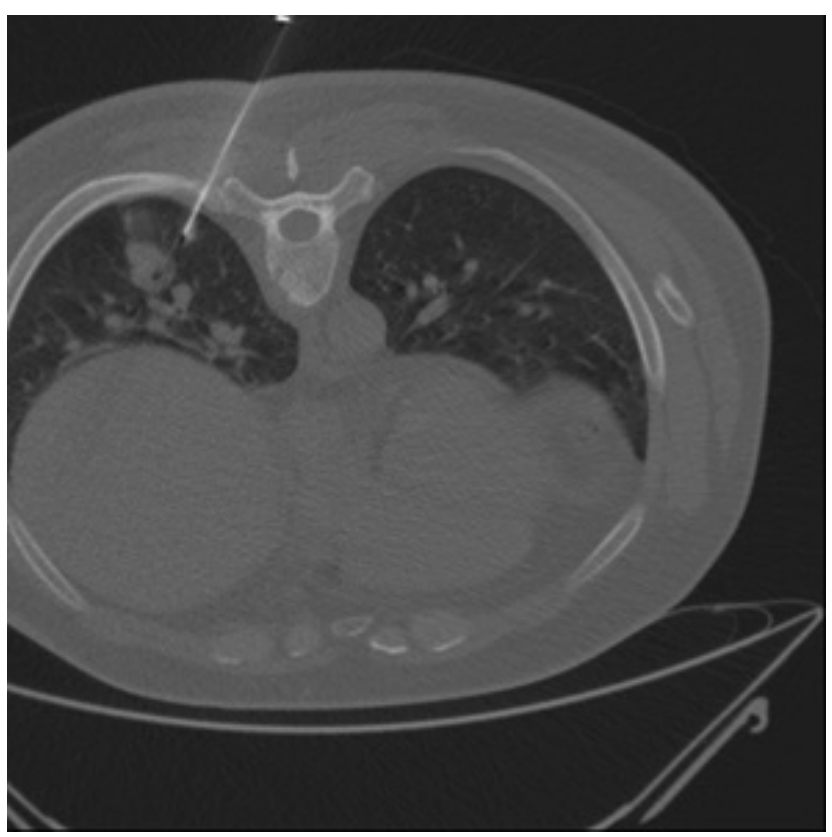

Olgu 1: 50 yaş erkek hasta sağ akciğer alt lobdaki kitleye yönelik prone pozisyonda alınan biopsi

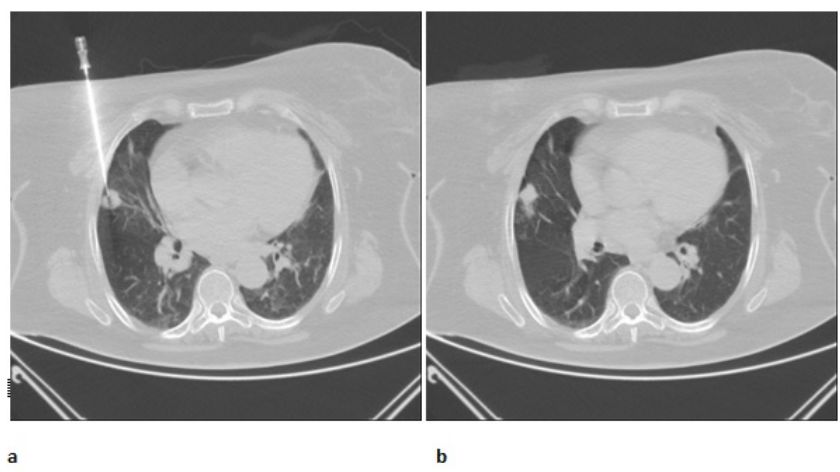

Olgu 2: 79 yaş kadın hasta, sağ akciğer orta lobdaki kitleye yönelik supin pozisyonda yapılan (a) biopsi işlemi ve (b) biopsi sonrası alınan görüntüsü. İşlem sonrası alınan kontrol görüntüde pnömotoraks izlenmemiş olup kitle posteriorunda minimal hemoraji seçilmekte

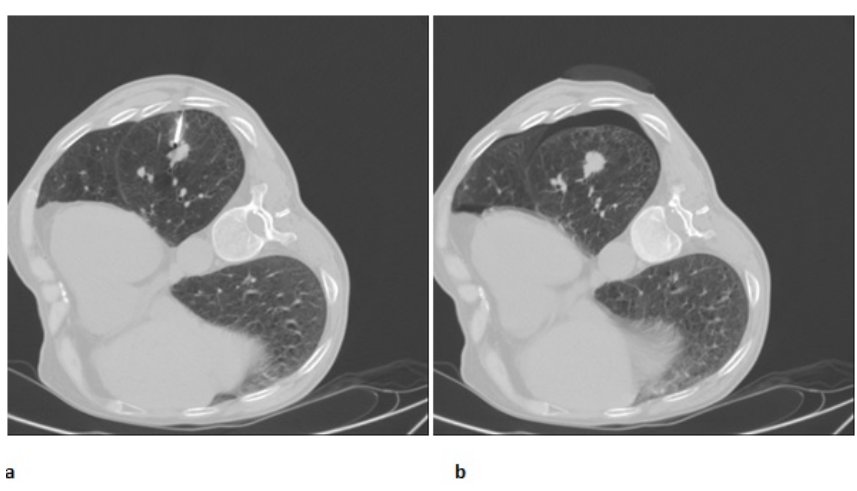

Olgu 3: Sol akciğer alt lobdaki kitleye yönelik lateral pozisyonda alınan (a) biopsi görüntüsü, (b) biopsi sonrası kontrol görüntüde hastada pnömotoraks izlenmekte 
Lezyon çapı ortancası 35,5 (49,0-23,50) mm olarak, iğne giriş uzunluğu ortancası ise 14,5 $(26,0-9,0)$ mm olarak bulundu.

Lezyon çapının çeşitli değişkenlere göre incelemesi yapıldığında erkeklerdeki lezyon çapı ortancası kadınlardan anlamlı şekilde yüksek bulunmuștur $(p<0,001)$. Segment ile lezyon çapı arasında anlamlı bir farklılık bulunmuştur ve bu farklılık üst lob ile orta lob arasındaki ve üst lob ile alt lob arasındaki farktan kaynaklanmıştır $(p<0,001)$. Malign hastaların lezyon çapı benign hastaların lezyon çapından anlamlı șekilde fazla bulunmuştur $(p=0,003)$. Lezyon çapı ile lokalizasyon, eşlik eden amfizem olma durumu, pozisyon, komplikasyon durumu, komplikasyon türü ve tüp takılma durumu arasında anlamlı iliş̧ki bulunamamıștır ( $p>0,05)$.

İğne giriş uzunluğunun çeşitli değişkenlere göre incelemesi yapıldığında komplikasyon gelişen hastalardaki iğne giriş uzunluğu ortancası komplikasyon gelişmeyen hastaların ortancasından anlamlı șekilde yüksek bulunmuştur $(p=0,005)$ (Şekil 1). Aynı şekilde komplikasyon olarak hemoraji gelişen hastaların iğne giriş̧ uzunluğu ortancası pnömotoraks gelişen hastaların ortancasından anlamlı şekilde fazla bulunmuştur $(\mathrm{p}=0,004)$ (Şekil 2). İğne giriş uzunluğu ile cinsiyet, lokalizasyon, segment, eşlik eden amfizem olma durumu, pozisyon, tüp takılma durumu ve tanı arasında anlamlı ilişki bulunamamıştır ( $p>0,05)$ (Tablo 2).

Tablo II: Lezyon çapı ve iğne giriş uzunluğunun çeşitli parametrelere göre ilişkisi

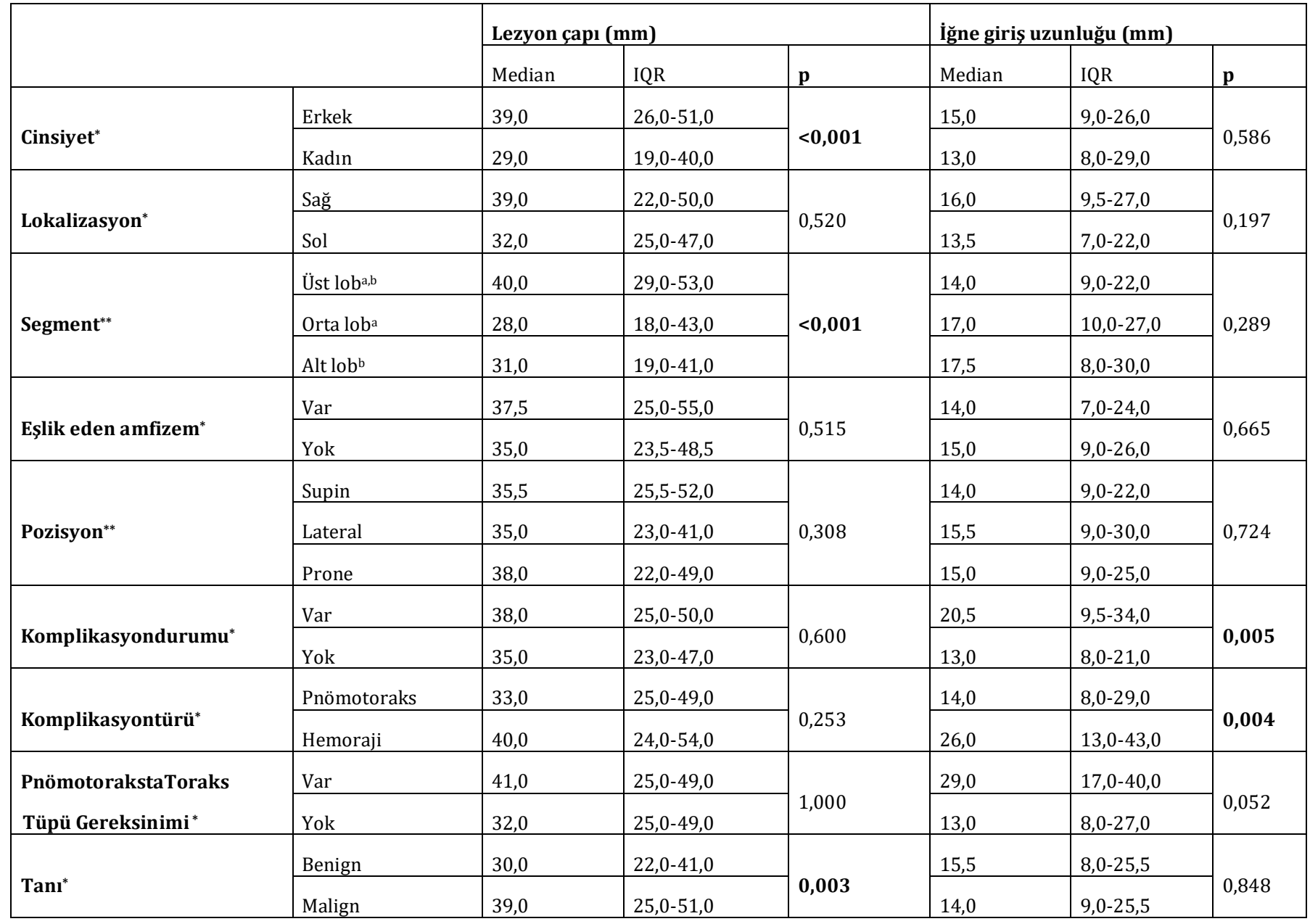

*Mann-Whitney U testi, **Kruskal Wallis testi kullanılmıştır.a,bFaklılığın kaynaklandığı grup 


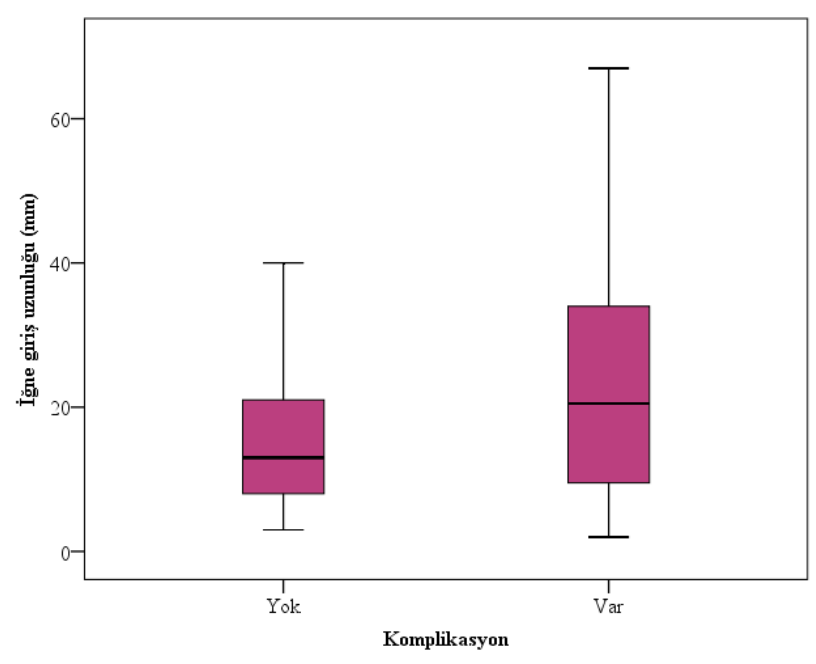

Şekil 1. Komplikasyon durumu ile iğne giriş uzunluğu ilişkisi

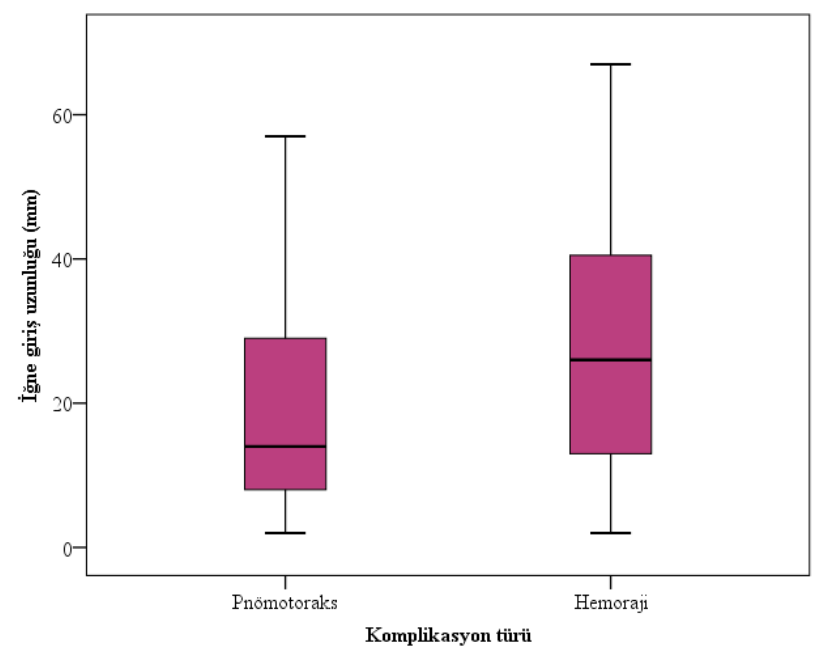

Şekil 2. Komplikasyon türü ile iğne giriş uzunluğu ilişkisi

Kadınların pnömotoraks gelişme oranı erkeklerinkinden anlamlı şekilde fazla bulunmuştur $(p=0,03)$. Hemoraji olmayanlarda pnömotoraks gelişme oranı hemoraji olanlardan anlamlı şekilde fazla bulunmuştur $(p<0,001)$. Pnömotoraks gelişme durumu ile lezyon çapı, iğne giriş uzunluğu, lokalizasyon, segment, eşlik eden amfizem varlığı, pozisyon ve tanı arasında anlamlı bir ilişki bulunamamıştır ( $p>0,05)$ (Tablo 3).

Yapılan korelasyon analizinde yaş ile lezyon çapı arasında anlamlı ilişki bulunamamıştır ( $\mathrm{r}=0,079, \mathrm{p}=0,148)$. Aynı şekilde yaş ile iğne giriş uzunluğu arasında da anlamlı bir ilişki bulunamamıștır ( $\mathrm{r}=-0,046, \mathrm{p}=0,449)$. Lezyon çapı ile iğne giriş uzunluğu arasında da anlamlı bir ilişki bulunamamıştır ( $r=0,054, \mathrm{p}=0,378)$.

Tablo III:Pnömotoraks Gelişme Durumunun Çeşitli Değişkenlere Göre İliş̧isi

\begin{tabular}{|c|c|c|c|c|c|c|}
\hline & & \multicolumn{2}{|c|}{$\begin{array}{l}\text { Pnömotorak } \\
\text { s yok } \\
\end{array}$} & \multicolumn{2}{|c|}{$\begin{array}{l}\text { Pnömotorak } \\
\text { s var }\end{array}$} & $\mathbf{p}$ \\
\hline \multicolumn{2}{|l|}{ Yaş (ort $\pm S S)^{*}$} & \multicolumn{2}{|c|}{$61,98 \pm 13,16$} & \multicolumn{2}{|c|}{$62,75 \pm 8,74$} & 0,577 \\
\hline \multicolumn{2}{|c|}{$\begin{array}{l}\text { Lezyon çapı-medyan } \\
\text { (IQR)** }^{* *}\end{array}$} & \multicolumn{2}{|c|}{$\begin{array}{ll}36,5 & (49,0- \\
23,0) & \\
\end{array}$} & \multicolumn{2}{|c|}{$\begin{array}{l}33,0 \quad(49,0- \\
25,0)\end{array}$} & 0,592 \\
\hline \multicolumn{2}{|c|}{$\begin{array}{l}\text { İğne giriş uzunluğu- } \\
\text { medyan (IQR)** }\end{array}$} & \multicolumn{2}{|c|}{$\begin{array}{l}15,0 \quad(25,0- \\
9,0)\end{array}$} & \multicolumn{2}{|c|}{$\begin{array}{l}14,0 \quad(29,0- \\
8,0)\end{array}$} & 0,619 \\
\hline \multirow{2}{*}{ Cinsiyet $^{* * *}$} & Erkek & 216 & 84,7 & 39 & 15,3 & \multirow{2}{*}{0,03} \\
\hline & Kadın & 60 & 74,1 & 21 & 25,9 & \\
\hline \multirow{2}{*}{ Hemoraji ${ }^{* * *}$} & Var & 55 & 100,0 & 0 &, 0 & \multirow{2}{*}{$\begin{array}{l}<0,00 \\
1\end{array}$} \\
\hline & Yok & 221 & 78,6 & 60 & 21,4 & \\
\hline \multirow{2}{*}{$\begin{array}{l}\text { Lokalizasyon* } \\
* *\end{array}$} & Sağ & 169 & 80,5 & 41 & 19,5 & \multirow{2}{*}{0,303} \\
\hline & Sol & 107 & 84,9 & 19 & 15,1 & \\
\hline \multirow{3}{*}{ Segment ${ }^{* * *}$} & $\begin{array}{l}\text { Üst } \\
\text { lob }\end{array}$ & 145 & 81,5 & 33 & 18,5 & \multirow{3}{*}{0,631} \\
\hline & $\begin{array}{l}\text { Orta } \\
\text { lob }\end{array}$ & 37 & 78,7 & 10 & 21,3 & \\
\hline & Alt lob & 94 & 84,7 & 17 & 15,3 & \\
\hline \multirow{2}{*}{$\begin{array}{l}\text { Eşlik eden } \\
\text { amfizem* }^{*}\end{array}$} & Var & 26 & 81,3 & 6 & 18,8 & \multirow{2}{*}{0,890} \\
\hline & Yok & 250 & 82,2 & 54 & 17,8 & \\
\hline \multirow{3}{*}{ Pozisyon $^{* * *}$} & Supin & 84 & 77,8 & 24 & 22,2 & \multirow{3}{*}{0,280} \\
\hline & $\begin{array}{l}\text { Latera } \\
1\end{array}$ & 73 & 82,0 & 16 & 18,0 & \\
\hline & Prone & 119 & 85,6 & 20 & 14,4 & \\
\hline \multirow{2}{*}{$\operatorname{Tan}^{* * *}$} & $\begin{array}{l}\text { Benig } \\
\mathrm{n}\end{array}$ & 62 & 80,5 & 15 & 19,5 & \multirow{2}{*}{0,705} \\
\hline & $\begin{array}{l}\text { Malig } \\
\mathrm{n}\end{array}$ & 197 & 82,4 & 42 & 17,6 & \\
\hline
\end{tabular}

*Bağımsız gruplarda t testi, **Mann-Whitney U testi, ${ }^{* * *}$ Kikare testi kullanılmıştır.

\section{TARTIŞMA}

Akciğer lezyonlarının tanısında görüntüleme yöntemleri oldukça önemli bir yer tutmaktadır. Ancak gelişen teknolojiye rağmen akciğer kitlelerinde tanıda altın standart histopatolojik 
incelemedir ${ }^{4,5}$. Maliyetinin düşük olması, hasta toleransının iyi olması, genel anestezi gerektirmemesi, kolay uygulanabilirliği gibi sebeplerle BT tanıda en çok kullanılan yöntemlerden biri olmuştur. Transtorasik biopsilerde ince iğne aspirasyon ve trucut biopsi yöntemleri bulunmaktadır. Yapılan çalışmalarda ince iğne biopsisinde tanısal doğruluk oranı malign lezyonlarda \%90-95 aralığında, benign lezyonlarda \%80-83 aralığında bildirilmiştir. Trucut biopsilerde tanısal doğruluk oranı benign lezyonlarda ortalama \%85, malign lezyonlarda ortalama \%95 olduğu bildirilmiștir4-8. Çalıșmamızda sadece trucut biopsi yapılmış hastalar bulunmakta olup ince iğne aspirasyon biopsisi serimizde çok az bulunması nedeniyle çalışmaya alınmamıştır. Çalışmamızda tanısı konulan hastaların \%24,4'ü benign iken, \%71,1'i malign olarak bulunmuştur. Hastalarımızın \%6'sinda materyal yetersiz bulunmuş olup herhangi bir tanıya gidilememiştir.

Akciğer lezyonlarının çapı, yerleşim yeri kullanılacak biopsi tekniği açısından oldukça önemlidir. Transtorasik biopsi yapılmış hastaların incelendiği çalışmalarda biopsi yapılan kitlelerde sağ ve üst lob hakimiyeti bildirilmiştir ${ }^{9,10,11}$. Bizim çalışmamızda literatür ile uyumlu olarak lezyonların \%62,5 i sağ lob ve $\% 53$ ü üst lob yerleşimliydi. Çalışmamızdaki ortalama lezyon çapı 35,5 mm ölçülmüş olup lezyon çapı erkeklerde anlamlı derecede yüksek bulunmuştur ( $\mathrm{p}:<0,001)$.Çalışmamızda ayrıca malign hastaların lezyon çapı benign hastaların lezyon çapından anlamlı şekilde fazla bulunmuştur $\quad(p=0,003) . \quad$ Transtorasik biopsilerde en önemli endikasyon akciğerdeki lezyonun malign olup olmadığını anlamaktır. Malign lezyon kriteri olarak spiküle kontur, heterojenite, ileri yaș, sigara öyküsü, takipte boyut artışı olması gibi durumlar bildirilmiștir. Nekrotik lezyonlarda biopsinin nekroz alanından alınması tanısal duyarlılığı düşürmektedir. Biopsi yaplacak lezyon karakteri ve biopsinin nerden alındığı tanısal duyarlılık açısından oldukça önemlidir ${ }^{12}$. Yapılan çalışmalarda lezyonların büyük çoğunluğunun noduler solid kitle şeklinde olduğu bildirilmiştir 9,10,11,13 . Çalışmamızda lezyon karakterleri değerlendirildiğinde en sık olarak $\% 46,4$ konsolidasyon ve $\% 41,4$ oranında nodüler karakterde görünüm mevcut olup lezyonların sadece \%8 i kaviter yapıdaydı. Biopsi sonrası hastaların \%94' ünde benign veya malign tanı konulmuştur.

Lezyona en kısa yolun seçilmesi, hastanın tolere edebilmesi ve interkostal mesafenin biopsiye engel olmaması nedeniyle biopsi sirasinda hastaya uygun pozisyonun verilmesi oldukça önemlidir. Yapılan çalışmalarda prone pozisyonunda alınan işlemlerde nefes hareketlerinin daha az olması, interkostal mesafenin daha geniş olması ve hasta anksiyetesinin daha az olması nedeniyle biopsi için daha uygun olduğu bildirilmiştir ${ }^{14}$. Çalışmamızda hastalar en sık \%41 oranında prone pozisyonunda işleme alınmış olup hastaya verilen pozisyon ile komplikasyon olarak pnömotoraks gelişmesi arasında anlamlı bir ilişki saptanmamıștır( $p>0,05)$.

Transtorasik akciğer biopsilerinde en sik komplikasyon pnömotoraks ve hemorajidir. Biyopsi nedeniyle ölüm genelde erken dönemde olmaktadır. Mortalite sebepleri akut masif hemoptizi veya pulmoner hemoraji, pulmoner venöz embolizme bağlı intraserebral ve koroner arterlerde hava ve büyük hemotorakstır. Yapılan çalışmalarda pnömotoraks gelişme oranı \%0-61 gibi geniş bir aralıkta tespit edilmiştir. Pnömotoraks gelișen hastaların büyük kısmında toraks tüpü gereksinimi bulunmamakta olup toraks tüpü gereksinimi değişik çalışmalarda \%1,5-21 aralığında bildirilmiştir9,13,15,16. Pulmoner hemoraji ikinci en sık komplikasyon olup çalışmalarda sıklığının \%5-27 arasında değiştiğ bildirilmiştir ${ }^{2,17}$. Bizim çalışmamızda hastaların 
$\% 17,8$ inde pnömotoraks, $\% 16,3$ ünde hemoraji gelișmiş olup pnömotoraks gelișen hastaların $\% 11,6$ sinda toraks tüpü gereksinimi olmuştur. Ayrıca pnömotoraks, kadın hastalarda anlamlı derecede yüksek bulunmuştur (p:0.03). Ancak pnömotoraks gelişme durumu ile lezyon çapı, iğne giriş uzunluğu, lokalizasyon, segment, eşlik eden amfizem varlığı, pozisyon ve tanı arasında anlamlı bir ilişki bulunamamıştır ( $p>0,05)$. Ayrıca çalışmamızda hemoraji olmayanlarda pnömotoraks gelişme orani, hemoraji olanlardan anlamlı şekilde fazla bulunmuştur $(\mathrm{p}<0,001)$.

Yapılan çalışmalarda pnömotoraks gelişme riskini arttıran faktörler arasında; lezyon boyutunun küçük olması, lezyon derinliğinin fazla olması, lezyonun alt loblarda yer alması, hastanın ileri yaşlarda olması sebebiyle nefes tutamaması, iğne ile fissür geçilmesi ve amfizem varlığının yer aldığı üzerine tartışmalar yapılmıştır18-19. Çalışma serimizdeki biopsi işlemlerinde hiçbir hastada fissür geçilmemiştir. Çalışmamızda biopsi iğnesinin parankimal alanda kat ettiği mesafe iğne giriş uzunluğu olarak tanımlanmış olup iğne giriş uzunluğu ile pnömotoraksa toraks tüpü gereksinimi ve tanı arasında anlamlı ilişki yoktu $(p>0,05)$. İğne giriş uzunluğunun çeşitli değişkenlere göre incelemesi yapıldığında komplikasyon gelişen hastalardaki iğne giriş uzunluğu ortancası komplikasyon gelişmeyen hastaların ortancasından anlamlı şekilde yüksek bulunmuştur $(p=0,005)$. Benzer şekilde komplikasyon olarak hemoraji gelişen hastaların iğne giriş uzunluğu ortancası, pnömotoraks gelișen hastaların ortancasından anlamlı şekilde fazla idi $(\mathrm{p}=0,004)$.

Sonuç olarak akciğer kitlelerinde trucut biopsi yapılmış hastalarımızda tanı oranı yüksek, komplikasyon oranı düşük olarak izlendi. BT akciğer kitle biopsilerinde kolay uygulanabilen, komplikasyonu erken dönemde gösterebilen oldukça etkin bir yöntemdir.
Etik Kurul Kararı: Çalışmamız Dicle Üniversitesi Tıp Fakültesi Girişimsel olmayan Klinik Araştırmalar Etik Kurulundan 09.01.2020 tarih ve 88 sayı numarası ile onay alınmıştır.

Çıkar Çatışması Beyanı: Yazarlar çıkar çatışması olmadığını bildirmişlerdir.

Finansal Destek: Bu çalışma her hangi bir fon tarafından desteklenmemiştir.

Declaration of ConflictingInterests: The authors declare that they have no conflict of interest.

Financial Disclosure: No financial support was received.

\section{KAYNAKLAR}

1. Manhire A, Charig M, Clelland C, et al. Guidelinesforradiologicallyguidedlungbiopsy.

Thorax 2003;58:920-36.

2. Düzgün F, Tarhan S. PerkütanTranstorasik Akciğer ve Kemik Biyopsileri. Trd Sem 2015; 3: 18291.

3. Lee W J, Chong S, Seo J S, Shim H J. Transthoracicfine-needleaspirationbiopsy of thelungsusing a C-armcone-beam CT system: diagnosticaccuracyandpostproceduralcomplication s. The British J Radiol 2012; 85: 217-22.

4. Aktaş AR, Gözlek E, Yılmaz Ö, ve ark. CTguidedtransthoracicbiopsy:

histopathologicresultsandcomplicationrates.

DiagnIntervRadiol 2015; 21: 67-70

5. Beslic S, Zukic F, Milisic S. Percutaneoustransthoracic CT guidedbiopsies of lunglesions;

fineneedleaspirationbiopsyversuscorebiopsy. RadiolOncol 2012; 46: 19-22.

6. Chami HA, Faraj W, Yehia ZA, et al. Predictors of pneumothoraxafter CTguidedtransthoracicneedlelungbiopsy: the role of quantitative CT. ClinRadiol. 2015; 70: 1382-7.

7. De Filippo M, Saba L, Silva M, et al. CTguidedbiopsy of pulmonarynodules: is pulmonaryhemorrhageacomplicationor an 
advantage? DiagnIntervRadiol. 2014 Sep-Oct; 20:421-5.

8. Li Y, Du Y, Yang HF, Yu JH, Xu XX. CTguidedpercutaneouscoreneedlebiopsyforsmall $(\leq 20$ $\mathrm{mm}$ ) pulmonarylesions. ClinRadiol 2013; 68: 43-8.

9. Tuncel P, Ergun O, Çetin N,ve ark. Bilgisayarlı tomografi eşliğinde perkütantranstorasik akciğer biyopsisi: tek merkez deneyimi. Ortadoğu Tıp Dergisi 2018; 10: 57-63.

10. Yüksekkaya R, Çelikyay F, Gökçe E, ve ark. Bilgisayarlı Tomografi ve Ultrasonografi Eşliğinde PerkütanToraks Biyopsileri: Tek Merkez Deneyimi. Gaziosmanpaşa Üniversitesi Tıp Fakültesi Dergisi 2014; 6: 269-80

11. Dere O, Kolu M, Ağyar A,ve ark. BT kılavuzluğunda transtorasik kesici iğne akciğer biyopsisi: tanısal etkinliği ve komplikasyon oranları. Harran Üniversitesi Tıp Fakültesi Dergisi 2019; 16: 227-230.

12. Yankelevitz DF, Henschke CI, Koizumi JH, Altorki NK, Libby D. CT-guidedtransthoracicneedlebiopsy of smallsolitarypulmonarynodules. ClinImaging 1997; 21: 107-10.

13. Arıba BK, Dingil G, Ahin G, ve ark. CTguidedtransthoracicbiopsy: Factors in pneumothorax risk anddiagnosticyield. Nobel Medicus 2019; 7: 1: 37-41.

14. Winokur RS, Bradley B, Sullivan BW, Madoff DC. Percutaneouslungbiopsy: technique, efficacy, andcomplications. Semin InterventRadiol 2013; 30: 121-7.

15. Kazerooni EA, Lim FT, Mikhail A, Martinez FJ. Risk of pneumothorax in CTguidedtransthoracicneedleaspirationbiopsy of thelung. Radiology 1996; 198: 371-5.

16. Topal U, Berkman YM. Effect of needletractbleeding on occurrence of pneumothoraxaftertransthoracicneedlebiopsy. Eur J Radiol 2005; 53: 495-8.

17. Takeshita J, Masago $K$, Kato $R$, et al. CTguidedfine-needleaspirationandcoreneedlebiopsies of pulmonarylesions: A single-centerexperiencewith 750 biopsies in Japan. AJR 2015; 204: 29-34.

18. Boskovic T, Stanic J, Pena-Karan S, et al. Pneumothoraxaftertransthoracicneedlebiopsy of lunglesionsunder CT guidance. JThoracDis 2014; 6: 99-107.

19. Cox J S, Chiles C, McManus C M, Aquino S L, Choplin R H. Transthoracicneedleaspirationbiopsy: variablesthataffect risk of pneumothorax. Radiology 1999; 212: 165-8. 